ORIGINAL ARTICLE

\title{
Lactobacillus delbrueckii subsp lactis (strain CIDCA 133) resists the antimicrobial activity triggered by molecules derived from enterocyte-like Caco-2 cells
}

\author{
A.A. Hugo ${ }^{1}$, G.L. De Antoni ${ }^{1,2}$ and P.F. Pérez ${ }^{1,2}$ \\ 1 Centro de Investigación y Desarrollo en Criotecnología de Alimentos (CIDCA-CCT CONICET), UNLP, La Plata, Argentina \\ 2 Departamento de Ciencias Biológicas, Facultad de Ciencias Exactas, Cátedra de Microbiología, UNLP, La Plata, Argentina
}

\section{Keywords}

cationic peptides, defensins, innate host

defence, lactobacilli, probiotics.

\section{Correspondence \\ Pablo F. Perez, Centro de Investigacion y Desarrollo en Criotecnología de Alimentos ICIDCA-CCT CONICET, La Plata; \\ Departamento de Ciencias Biológicas, \\ Facultad de Ciencias Exactas, Cátedra de \\ Microbiología, UNLP, Calle 47 y 116, La Plata \\ (1900), Argentina. \\ E-mail:pfp@biol.unlp.edu.ar}

2009/0990: received 4 June 2009, revised 21 December 2009 and accepted 22 December 2009

doi:10.1111/j.1472-765X.2010.02796.x

\begin{abstract}
Aims: The aim of the present study was to assess the ability of a potentially probiotic strain to resist, in vitro, the effect of intestinal antimicrobial molecules.

Methods and results: Strain CIDCA 133 of Lactobacillus delbrueckii subsp lactis was studied. Lactobacillus delbrueckii subsp bulgaricus as well as other grampositive and gram-negative bacteria were used for comparison purposes. The effect of different antimicrobial extracts was determined by diffusion assays, viable counts and growth kinetics. Human-defensins ( $h \beta \mathrm{D} 1$ and $\mathrm{h} \beta \mathrm{D} 2)$ were also included in the study. Two types of cellular fractions from Caco-2 cells were tested: (i) cytosolic fractions, obtained by sonication of cultured human enterocytes and (ii) cationic fraction, obtained by batch extraction of the cytosolic fraction with a weak cation exchange resin. In addition, the effect of Caco-2-secreted factors was studied. Strain CIDCA 133 was neither inhibited by Caco-2 secreted, cytosolic nor cationic fractions. Of note, human-defensins were inactive against strain CIDCA 133. In contrast, a related lactobacilli: Lactobacilli delbrueckii subsp bulgaricus (strain CIDCA 331) and other species of gram-positive or gram-negative bacteria were strongly inhibited.

Conclusions: Strain CIDCA 133 is able to survive and grow in the presence of enterocyte-derived antimicrobial molecules. This ability is not a general property of lactobacilli.

Significance and Impact of the Study: Results could provide a new insight into the mechanisms of the probiotic effect and encourage further studies on this field. Resistance to antimicrobial peptides can be relevant to understand the interaction of potentially probiotic strains with the host's immune system. This ability can be also relevant as a selection criterion for new probiotic strains.
\end{abstract}

\section{Introduction}

Probiotics are defined as 'live microbial food supplements that improve the health of the host' (Fuller 1989). Fermented dairy products containing probiotic bacteria are the most successful category of functional foods (Saxelin et al. 2005). Lactobacilli and bifidobacteria are generally accepted as suitable candidates for the formulation of probiotics for humans. Consumption of probiotics positively affects the composition of intestinal microbiota and could provide several benefits for the host including the inhibition of intestinal pathogens, immunomodulation, anticarcinogenic and antimutagenic activities, alleviation of symptoms of lactose intolerance and reduction in serum cholesterol (Hord 2008). Selection criteria of potentially probiotic strains include several recommendations as technological adaptability, accurate identification, GRAS status and capacity to survive, proliferate and 
develop their metabolic activity in vivo (Klaenhammer and Kullen 1999). Also, acid-bile tolerance and adherence to epithelial cells are considered as relevant characteristics in a probiotic strain (Mishra and Prasad 2005).

There are multiple factors that could affect the viability of probiotic micro-organisms in the gastrointestinal tract. The intestinal mucosa is protected from the attack of harmful enteric micro-organisms by host's defences in the context of both adaptive and innate immunity. Innate immunity, the first line of defence, uses nonclonal recognition molecules and nonspecific effector molecules. Epithelial cells are the main players of innate immunity by providing a physical barrier against bacterial translocation as well as by producing several biologically active molecules. These factors, along with the resident microbiota, control pathogenic micro-organisms (Ganz 2002). The nonspecific effector molecules produced by the intestinal epithelia include, mucins, enzymes, histones and antimicrobial peptides (AMPs) such as defensins (Hecht 1999). These molecules could be either secreted to the extracellular milieu or remain in the cytoplasm and nuclei of the epithelial cells (Rose et al. 1998). AMPs are relatively small proteins (12-100 amino acids), positively charged, amphiphillic, and they have a broad antimicrobial spectrum (Jenssen et al. 2006). Antimicrobial intestinal peptides are produced by specialized cells (Paneth's cells) and also by epithelial cells (Liévin-Le Moal and Servin 2006).

Human epithelial intestinal cells produce two types of AMPs: $\beta$ defensins (h $\beta \mathrm{D}-1$ and $\mathrm{h} \beta \mathrm{D}-2$ ) and the cathelicidin hLL-37. At mucosal surfaces, AMPs can modify the balance of the colonizing microbiota (Salzman et al. 2007).

The aim of the present study was to assess the in vitro effect on potentially probiotic lactobacilli of antimicrobial factors present in cultured human enterocytes.

\section{Materials and methods}

\section{Bacterial strains and growth conditions}

Shigella flexneri, Escherichia coli CM1, Bacillus cereus M2 and enteropathogenic Escherichia coli (EPEC) belong to the culture collection of the Cátedra de Microbiología of the Facultad de Ciencias Exactas (Universidad Nacional de La Plata, Argentine). Lactobacillus delbrueckii subsp. lactis strain CIDCA 133 and Lactobacillus delbrueckii subsp bulgaricus strain CIDCA 331 belong to the culture collection of the Centro de Investigación y Desarrollo en Criotecnología de Alimentos. (CIDCA, Facultad de Ciencias Exactas, Universidad Nacional de La Plata, Argentine). Stock cultures were stored at $-80^{\circ} \mathrm{C}$, and micro-organisms were reactivated twice in liquid medium before the experiments. Gram-negative bacteria were grown in nutrient broth (Biokar Diagnostics, Beauvais, France) at $37^{\circ} \mathrm{C}$ for $16 \mathrm{~h}$. Bacillus cereus was cultured in Brain Heart Infusion (BHI) broth (Biokar Diagnostics, Beauvais, France) containing $01 \%(\mathrm{w} / \mathrm{v})$ glucose at $32^{\circ} \mathrm{C}$ under orbital agitation. Incubation was performed for $3 \mathrm{~h}$ to obtain bacteria in early stationary phase thus minimizing the ratio of sporulated $B$. cereus. Lactobacilli were grown in de Man, Rogosa, Sharp (MRS) broth (Biokar Diagnostics, Beauvais, France) in anaerobic conditions at $37^{\circ} \mathrm{C}$ for $16 \mathrm{~h}$. Bacteria were harvested by centrifugation at $10000 \mathrm{~g}$ for $10 \mathrm{~min}$ and suspended in phosphate buffered saline (PBS) or the appropriate growth medium.

\section{Cell cultures}

Caco-2 cells were cultured in $75-\mathrm{cm}^{2}$ flasks $\left(37^{\circ} \mathrm{C}, 5 \%\right.$ $\mathrm{CO}_{2}-95 \%$ air atmosphere) in Dulbecco's Modified Eagle's Medium (DMEM; Gibco BRL, Life Technologies, Rockville, MD, USA) supplemented with $10 \%(\mathrm{v} / \mathrm{v})$ of foetal calf serum (PAA; Laboratories, GmbH, Pasching, Austria), 1\% nonessential amino acids (Gibco, BRL, Life Technologies) and antibiotics (12 UI ml $\mathrm{m}^{-1}$ penicillin and $12 \mu \mathrm{g} \mathrm{ml}^{-1}$ streptomycin). Monolayers at postconfluence (15 days of incubation) were used throughout. Forty-four hours before the experiments, Caco-2 cells were incubated in DMEM medium without neither foetal calf serum nor antibiotics to avoid the presence of inhibitory compounds other than those produced by the epithelial cells.

\section{Caco-2-secreted factors}

After the incubation of cell monolayers with DMEM without foetal calf serum nor antibiotics, spent culture supernatant was collected, lyophilized and suspended in distilled water to obtain ten-fold concentrated extracts. Samples were stored at $-20^{\circ} \mathrm{C}$ until use.

\section{Caco- 2 cytosolic and brush border extracts}

Cytosolic fractions were obtained according to the protocol of Pinto et al. (1983). Briefly, cells were collected and washed thrice using cold PBS. Then, they were suspended in Tris-Manitol buffer $\left(2 \mathrm{mmol} \mathrm{l}^{-1}\right.$ Tris, $50 \mathrm{mmol} \mathrm{l}^{-1}$ manitol, pH 7•1). Afterwards, cell suspensions were incubated on ice and sonicated thrice for $30 \mathrm{~s}$ in an Ultrasonic Desintegrator, (Model $60 \mathrm{w}$; MSE Ltd., USA) The lysate was incubated with $\mathrm{CaCl}_{2}\left(10 \mathrm{mmol}^{-1}\right)$ for $10 \mathrm{~min}$ at $4^{\circ} \mathrm{C}$ and centrifuged at $950 \mathrm{~g}$ for $10 \mathrm{~min}$. Resulting supernatant was centrifuged at $33500 \mathrm{~g}$ for $30 \mathrm{~min}$ at $4^{\circ} \mathrm{C}$. After this step, two fractions were obtained: supernatant (cytosolic fraction) and pellet (brush border fraction). Cytosolic fraction was concentrated (ten-fold) by lyophilization as described earlier. 
Batch extraction of the cationic fraction from cytosol

Batch extraction was used to concentrate the cationic fraction from cytosol (Porter et al. 1998). Cytosolic fraction was incubated with a weak cation exchange resin (Macro-Prep CM; Bio-Rad Laboratories, CA, USA) at a ratio of $1: 200$ (resin : sample). After being incubated overnight at $4^{\circ} \mathrm{C}$ with gentle stirring, the resin was separated by centrifugation $(1500 \mathrm{~g}, 5 \mathrm{~min})$. Afterwards, three washes with sodium phosphate buffer $\left(10 \mathrm{mmol}^{-1}\right)$ were performed. Adsorbed cations were eluted at $4^{\circ} \mathrm{C}$ by two steps of acid treatment i.e. $1 \mathrm{~h}$ in $10 \%(\mathrm{v} / \mathrm{v})$ acetic acid and overnight in $5 \%(\mathrm{v} / \mathrm{v})$ acetic acid. Supernatants collected from both extractions were pooled, concentrated by lyophilization and stored at $-20^{\circ} \mathrm{C}$ until use.

\section{Inhibition assays}

Diffusion assays.

Antimicrobial activity of Caco-2 extracts was determined by using a diffusion assay as described by Lehrer et al.(1991). Briefly, solid media were obtained by adding $1 \%(\mathrm{w} / \mathrm{v})$ agarose to nutrient or MRS broth. Bacterial suspensions $\left(1 \times 10^{8} \mathrm{CFU} \mathrm{ml} \mathrm{ml}^{-1}\right)$ were spread on the surface of solid medium by using a cotton swab. Afterwards, $10 \mu \mathrm{l}$ of samples was added to wells $(25 \mathrm{~mm}$ in diameter) performed in the agarose. Plates were incubated for $24 \mathrm{~h}$ at $37^{\circ} \mathrm{C}$, and zone diameters were measured.

Assays in liquid media.

To assess the effect of inhibitory factors on the growth kinetics of the strains under study, Caco-2 extracts or human $\beta$-defensins ( $h \beta D 1$ and $h \beta D 2$; Sigma-Aldrich Co., St Louis, MO, USA) were added to bacterial suspensions $\left(1 \times 10^{5} \mathrm{CFU} \mathrm{m}^{-1}\right)$ in MRS or nutrient broth. $\beta$-defensins were used at $0-5 \mu \mathrm{g} \mathrm{ml}^{-1}$. The number of surviving bacteria was determined by plating appropriate dilutions on either nutrient or MRS agar.

\section{Statistical analysis}

Results were compared by means of the two-tailed Student's $t$-test using InfoStat Software (Grupo InfoStat, FCA, Universidad Nacional de Córdoba, Argentina).

\section{Results}

\section{Effect of Caco-2 extracts on micro-organisms}

To investigate the effect on different micro-organisms of cellular fractions obtained from Caco-2 cells, diffusion assays were conducted in culture media solidified with agarose. Incubation of either the Caco- 2 cytosolic fraction

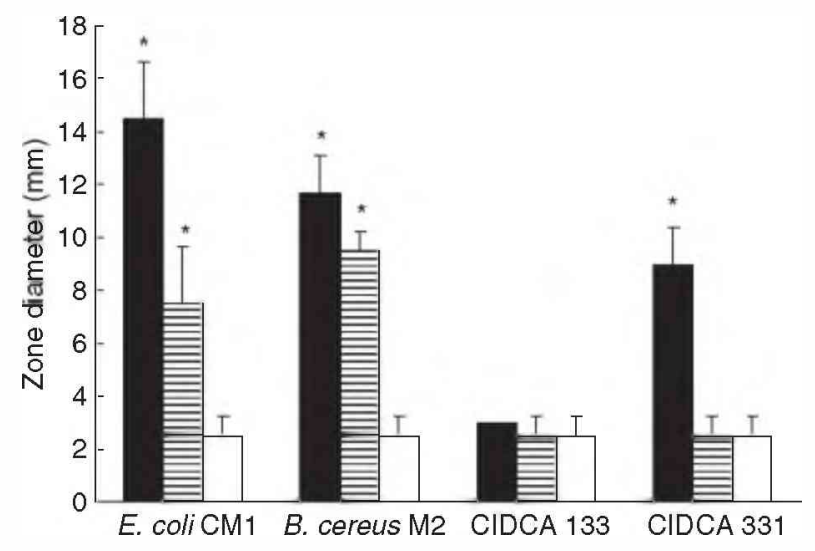

Figure 1 Effect of cytosolic and brush border fractions derived from Caco-2 cells on different bacterial strains. Antimicrobial activity was determined by diffusion assays (agarose). Micro-organisms were incubated with cytosolic fraction (black bars), brush border fraction (striped bars) or phosphate buffered saline (PBS) (white bars). Data represent the means of zone diameters \pm standard deviation $(n=3)$. Asterisks indicate significant differences with the corresponding PBS control $(P<0.05)$. Internal diameter of the wells was $2.5 \mathrm{~mm}$.

or the brush border fraction with different bacteria revealed an inhibitory effect. The antagonism was observed both on gram-positive and gram-negative bacteria (Fig. 1). Of note, whereas Shigella flexneri was strongly inhibited by both cytosolic and brush border fractions (zone diameters $14.5 \pm 2.2$ and $11^{-1} \pm 1.4 \mathrm{~mm}$, respectively), enteropathogenic E. coli (EPEC) was only inhibited by the cytosolic fraction (zone diameter $7 \cdot 0 \pm 1 \cdot 4 \mathrm{~mm}$ ). Interestingly, L. delbrueckii subsp lactis CIDCA 133 was not antagonized neither by the cytosolic nor the brush border extract from Caco-2 cells. In contrast, the related micro-organism Lactobacillus delbrueckii subsp bulgaricus strain CIDCA 331 was strongly inhibited by the cytosolic fraction. In addition, ten-fold concentrated spent culture supernatants from Caco- 2 cells were assayed. Even though inhibition zones of $13 \pm 1$ $\mathrm{mm}$ and $14 \pm 1 \mathrm{~mm}$ were observed for strains 331 and $\mathrm{CM} 1$, respectively, no inhibition on strain 133 was detected (zone diameter $25 \pm 0-0 \mathrm{~mm}$ ).

It is worth noting that assays performed by using agar, instead of agarose, as the solidifying agent led to smaller zone diameters (data not shown).

\section{Characterization of the inhibitory activity}

To distinguish between bacteriostatic and bactericidal activities, we performed assays in liquid medium. As shown in Fig. 2, incubation of E. coli CM1 with cytosolic fraction from Caco-2 cells led to a $3-\log$ reduction in bacterial viability after $3-\mathrm{h}$ incubation. This bactericidal effect was also observed for strain 331 . Indeed, after $3-\mathrm{h}$ 


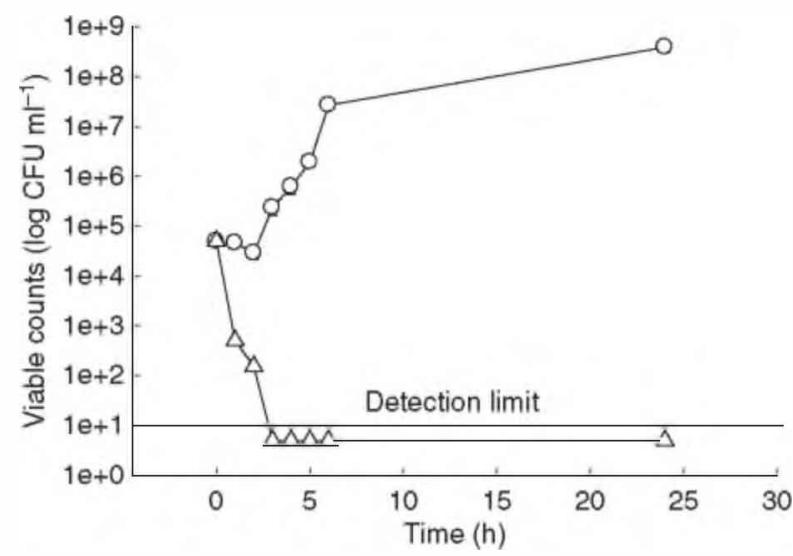

Figure 2 Killing effect of cytosolic fraction extract from Caco-2 cells against Escherichia coli strain CM1. Results show a representative kinetics. ( $\triangle$ ) cytosolic extract, $(O)$ control.

Table 1 Comparison of the effect on different micro-organisms of cytosolic and cationic extracts from Caco-2 cells

\begin{tabular}{lll}
\hline Strain & $\begin{array}{l}\text { Cytosolic } \\
\text { extract }\end{array}$ & $\begin{array}{l}\text { Cationic } \\
\text { extract }\end{array}$ \\
\hline Escherichia coli CM1 & ++ & + \\
Bacillus cereus M2 & ++ & + \\
Lactobacillus delbrueckil subsp & + & + \\
bulgaricus (CIDCA 331) & & - \\
Lactobacillus delbrueckil subsp & - & \\
lactis (CIDCA 133) & & \\
\hline
\end{tabular}

Results are scored according to the size of zone diameter in the diffusion assay. (+) 5-10 mm of inhibition zone; (++) 11-20 mm; (-) indicates no inhibitory effect $(2.5 \mathrm{~mm}$ corresponding to the diameter of the well).

incubation with cytosolic extracts, viable counts of strain 331 decreased from $10^{4} \mathrm{CFU} \mathrm{ml} l^{-1}$ to $10^{3} \mathrm{CFU} \mathrm{ml}{ }^{-1}$.

The findings that zone diameters in diffusion assays performed with agarose were larger than those obtained in agar-containing media, prompted us to investigate the role of cationic compounds in the inhibitory effect. To this end, we performed batch extraction of the cytosolic fraction from Caco-2 cells with a weak cation exchange resin. As given in Table 1, cationic fractions from Caco-2 cells showed similar inhibition pattern that cytosolic extracts.

\section{Effect of human $\boldsymbol{\beta}$-defensins}

Even though several positively charged molecules (e.g. histones, phospholipase A2, defensins) could be present in the cationic extracts, the fact that human beta-defensins $(\mathrm{h} \beta \mathrm{Ds})$ are the most abundant antimicrobial peptides in

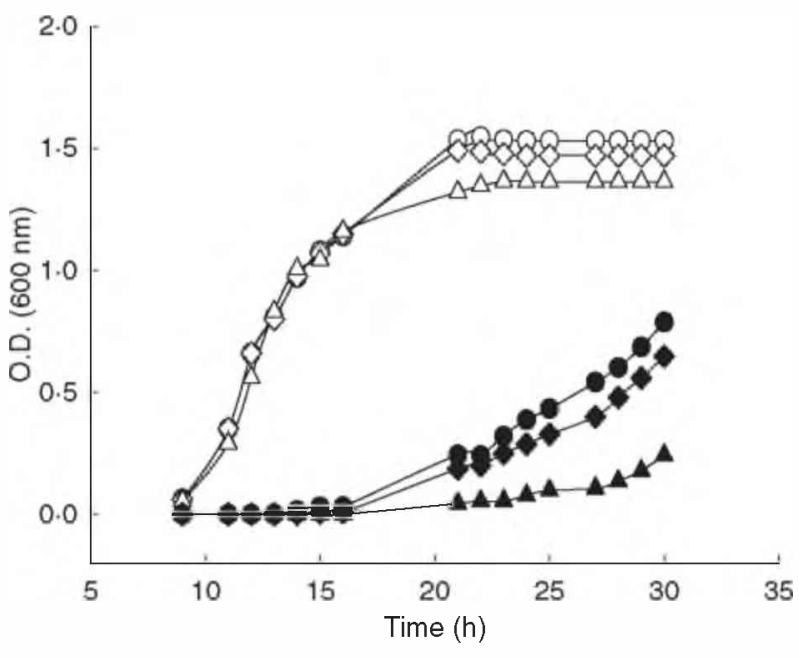

Figure 3 Growth curves of lactobacilli in the presence of human $\beta$-defensins. Symbols: $(\bullet, O)$ control; $\langle\triangle, \boldsymbol{\Delta}) \mathrm{h} \beta \mathrm{D}_{1} ;(\diamond, \bullet) \mathrm{h} \beta \mathrm{D}_{2}$. White symbols correspond to strain CIDCA 133, and black symbols correspond to strain CIDCA 331.

epithelial cells (Yanagi et al. 2007), prompted us to study the effect of purified human defensins.

Growth kinetics of lactobacilli performed in the presence of human $\beta$-defensins $\left(\mathrm{h} \beta \mathrm{D}_{1}\right.$ and $\left.\mathrm{h} \beta \mathrm{D}_{2}\right)$ showed that whereas Lactobacillus delbrueckii subsp bulgaricus CIDCA 331 was inhibited by both defensins (mainly by $\mathrm{h} \beta \mathrm{D} 2$ ), growth kinetics of Lactobacillus delbrueckii subsp lactis CIDCA 133 was not modified by defensins (Fig. 3). No effects were observed on the growth of E. coli CM1 in the presence of human defensins (data not shown).

\section{Discussion}

Survival of probiotic micro-organisms in the gastrointestinal tract depends on the ability to cope with several antimicrobial molecules produced by different cell populations.

Caco- 2 cells constitute a widely accepted model for the study of the interaction between micro-organisms and cell populations relevant to the defence mechanisms of the intestinal tract. It is known that Caco-2 cells are able to produce a set of molecules with antibacterial activity e. g. lysozyme, defensins, phospholipases and $\alpha$-antitrypsin (Bernet-Camard et al. 1996; Ganz 2002). In the present study, we used Caco-2-derived extracts to assess the effect of such inhibitory molecules on intestinal bacteria.

Whereas cytosolic extracts were inhibitory to most of the strains under study, strains CIDCA 133 and enteropathogenic E. coli (EPEC) showed a different behaviour, i.e. strain 133 was not inhibited, and EPEC was inhibited but in a lesser extent than other strains. This behaviour 
could be expected for a pathogenic micro-organism (EPEC), but, surprisingly, a nonpathogenic and potentially probiotic micro-organism such as strain CIDCA 133 was also able to resist the inhibitory effect of Caco-2derived factors. Furthermore, a different Lactobacillus strain was strongly inhibited by cytosolic extracts (Fig. 1). Noteworthy, concentrated spent supernatants from Caco2 cell cultures inhibited both E. coli CM1 and L. delbreuckii subsp bulgaricus CIDCA 331, thus indicating that, in contrast to strain 133 , these strains would not be active in the presence of secreted factors from enterocytes.

Defensins as well as other cationic molecules with antibacterial activity are important effectors of the innate immune system. Strain CIDCA 133 was resistant not only to the effect of the Caco- 2 cationic extract but also to purified human $\beta$ defensins (Table 1, Fig. 3).

The observed effect depends on the defensin/bacteria ratio. Indeed, when $10^{3} \mathrm{CFU} \mathrm{ml}^{-1}$ was incubated for $24 \mathrm{~h}$ with different concentrations of human $\beta$-defensins, we found that strains CM1 and 133 were able to grow in the presence of 5 and $25 \mu \mathrm{g} \mathrm{ml}^{-1}$ of human betadefensins, respectively, whereas strain 331 is able to grow at the concentrations of $0-08 \mu \mathrm{g} \mathrm{ml}^{-1} \mathrm{hBD}$ (data not shown). It is worth noting that concentration of $\mathrm{h} \beta \mathrm{D} 2$ in human faeces ranges from $0-01$ to $0-06 \mu \mathrm{g} \mathrm{ml}^{-1}$ (Möndel et al. 2009).

Antimicrobial peptides (AMPs) lead to antimicrobial effect by damaging or destabilizing cytoplasmic membrane or acting at cytoplasmic level by inhibiting essential cellular process such as protein or nucleic acid synthesis (Brogden 2005). Regardless of their precise mode of action, the activities of AMPs are almost universally dependent upon interaction with the bacterial cell membrane (Hancock and Rozek 2002). Interactions between antimicrobial peptides and bacteria are determined by electrostatic attraction between the positive-charged AMPs and anionic bacterial structures such as lipids and other surface structures (Jenssen et al. 2006).

Bacterial pathogens have evolved mechanisms to limit the effectiveness of AMPs. These mechanisms involve the diminution of the electrostatic interaction between AMPs and bacterial surface by reducing the net negative charge of the bacterial cell envelope through the covalent modification of anionic molecules such as lipid A, teichoic acids or phospholipids (Peschel 2002).

As strain CIDCA 133 was affected neither by the cationic extract from Caco-2 cells nor by purified human $\beta$ defensins, whereas strain CIDCA 331 was strongly inhibited, we could hypothesize that these strains differ in the composition of lipids or teichoic acids. In fact, chromatographic analysis revealed the different proportions of fatty acids present in cellular lipids between the two strains (Gómez Zavaglia et al. 2000).
The ability of probiotic micro-organisms to induce the production of antimicrobial molecules has been reported. Indeed, probiotic bacteria provoked a strong induction of $\mathrm{h} \beta \mathrm{D} 2$ synthesis in intestinal epithelial cells Caco-2 (Schlee et al. 2007, 2008). Furthermore, in vivo studies demonstrated that oral administration of potentially probiotic E. coli strains increases faecal secretion of $\mathrm{h} \beta \mathrm{D} 2$ in healthy volunteers (Möndel et al. 2009). It is worth noting that this probiotic strain was not resistant to the induced antimicrobial factors such as $\mathrm{h} \beta \mathrm{D} 2$. These findings could indicate the possibility of a suicidal character of this interaction (Möndel et al. 2009).

Lactobacillus delbrueckii subsp lactis CIDCA 133 demonstrated the ability to antagonize biological effect of enterohaemorrhagic E. coli (EHEC) in vitro and to inhibit nitrate reductase activity of a nonpathogenic commensal E. coli strain (Hugo et al. 2006, 2008). In the present study, we showed the ability of this strain to resist the effects of antimicrobial factors derived from cultured human enterocytes as well as to overcome the inhibitory effect of human $\beta$ defensins. These findings could be relevant to predict the competitiveness of this strain in vivo and to understand the interaction of selected probiotic micro-organisms with host's cells and the resulting immune response.

\section{Acknowledgements}

Financial support of CONICET, Agencia Nacional de Promoción Científica y Tecnológica and Facultad de Ciencias Exactas, UNLP is greatly acknowledged. AAH is a posdoc fellow of the CONICET, Argentine. GDA is a member of the Carrera de Investigador Científico $y$ Tecnologico of the CIC- PBA, Argentine. PFP is a member of the Carrera de Investigador Científico $y$ Tecnologico of the CONICET, Argentine.

\section{References}

Bernet-Camard, M.F., Coconnier, M.H., Hudault, S. and Servin, A.L. (1996) Differentiation-associated antimicrobial functions in human colon adenocarcinoma cell lines. Exp Cell Res 226, 80-89.

Brogden, K.A. (2005) Antimicrobial peptides: pore formers or metabolic inhibitors in bacteria? Nat Rev Microbiol 3, 238-250.

Fuller, R.. (1989) Probiotics in man and animals. J Appl Bateriol 66, 365-378.

Ganz, T. (2002) Ephitelia: not just physical barriers. Proc Natl Acad Sci 99, 3357-3358.

Gómez Zavaglia, A., Disalvo, E.A. and De Antoni, G.L. (2000) Fatty acid composition and freeze-thaw resistance in lactobacilli. J Dairy Res $67,241-247$. 
Hancock, R.E. and Rozek, A. (2002) Role of membranes in the activities of antimicrobial cationic peptides. FEMS Microbiol Lett 206, 143-149.

Hecht, G. (1999) Innate mechanisms of epithelial host defense: spotlight on intestine. Am J Physiol 277, 351-358.

Hord, N.G. (2008) Eukaryotic-microbiota crosstalk: potential mechanisms for health benefits of prebiotics and probiotics. Annu Rev Nutr 28, 215-231.

Hugo, A.A., De Antoni, G.L. and Pérez, P.F. (2006) Lactobacillus delbrueckii subsp lactis strain CIDCA 133 inhibits nitrate reductase activity of E. coli. Int J Food Microbiol 111, 191-196.

Hugo, A.A., Kakisu, E.J., De Antoni, G.L. and Pèrez, P.F. (2008) Lactobacilli antagonize biological effects of enterohaemorrhagic Escherichia coli in vitro. Lett Appl Microbiol 46, 613-619.

Jenssen, H., Hamill, P. and Hancock, R.E. (2006) Peptide antimicrobial agents. Clin Microbiol Rev 19, 491-511.

Klaenhammer, T.R. and Kullen, M.J. (1999) Selection and design of probiotics. Int J Food Microbiol 50, 45-57.

Lehrer, R.I., Rosenman, M., Harwig, S.S., Jackson, R. and Eisenhauer, P. (1991) Ultrasensitive assays for endogenous antimicrobial polypeptides. J Immunol Methods 137, 167-173.

Liévin-Le Moal, V. and Servin, A.L. (2006) The front line of enteric host defense against unwelcome intrusion of harmful microorganisms: mucins, antimicrobial peptides, and microbiota. Clin Microbiol Rev 19, 315-337.

Mishra, V. and Prasad, D.N. (2005) Aplication of in vitro methods for selection of Lactobacillus casei strains as potential probiotics. Int J Food Microbiol 103, 109-115.

Mōndel, M., Schroeder, B.O., Zimmermann, K., Huber, H., Nuding, S., Beisner, J., Fellermann, K., Stange, E.F. et al. (2009) Probiotic E. coli treatment mediates antimicrobial human beta-defensin synthesis and fecal excretion in humans. Mucosal Immunol 2, 166-172.
Peschel, A. (2002) How do bacteria resist human antimicrobiol peptides? Trends Microbiol 10, 179-186.

Pinto, M., Robine-Leon, S., Appay, M., Kedinger, M., Triadou, N., Dussaulx, E., Lacroix, B., Simmon-Assmann, P. et al. (1983) Enterocyte-like differentiation and polarization of the human colon carcinoma cell line Caco-2 in culture. Bio Cell 47, 323-330.

Porter, E.M., Poles, M.A., Lee, J.S., Naitoh, J., Bevins, C.L. and Ganz, T. (1998) Isolation of human intestinal defensins from ileal neoblader urine. FEBS Lett 434, 272-276.

Rose, F.R.A.J., Bailey, K., Keyte, J.W., Chan, W.C., Greenwood, D. and Mahida, Y.R. (1998) Potential role of epithelial cell-derived histone $\mathrm{H} 1$ proteins in innate antimicrobial defense in the human gastrointestinal tract. Infect Immun 66, 3255-3263.

Salzman, N.H., Underwood, M.A. and Bevins, C.L. (2007) Paneth cells, defensins, and the commensal microbiota: a hypothesis on intimate interplay at the intestinal mucosa. Semin Immunol 19, 70-83.

Saxelin, M., Tynkkynen, S., Mattila-Sandholm, T. and de Vos, W.M. (2005) Probiotics and other functional microbes: from markets to mechanisms. Curr Opin Biotech 16, 204-211.

Schlee, M., Wehkamp, J., Altenhoefer, A., Oelschlaeger, T.A., Stange, E.F. and Fellermann, K. (2007) Induction of human beta-defensin 2 by the probiotic Escherichia coli Nissle 1917 is mediated through flagellin. Infect Immun 75, 2399-23407.

Schlee, M., Harder, J., Köten, B., Stange, E.F., Wehkamp, J. and Fellermann, K. (2008) Probiotic lactobacilli and VSL\#3 induce enterocyte beta-defensin 2. Clin Exp Immuno 151, 528-535.

Yanagi, S., Ashitani, J., Imai, K., Kyoraku, Y., Sano, A., Matsumoto, N. and Nakazato, M. (2007) Significance of human beta-defensins in the epithelial lining fluid of patients with chronic lower respiratory tract infections. Clin Microbiol Infect 13, 63-69. 